\title{
Stroke: "striking reductions" are seen in number of people with symptoms seeking help
}

\author{
Jacqui Thornton
}

London

People are ignoring stroke symptoms and failing to ring 999 because they fear being a burden on the NHS in England during the covid-19 pandemic, the national clinical director for stroke has warned.

Deb Lowe, consultant stroke physician at Wirral University Teaching Hospital, said that doctors across the country were seeing "quite striking reductions" in the number of people coming into hospital with symptoms of stroke. She said, "It appears that people aren't seeking emergency help or going to hospital when they suspect a stroke, possibly due to fear of the virus or not wanting to be a burden on the NHS."

Last year there were almost 90000 strokes in England, and almost 21000 patients were admitted to hospital with a transient ischaemic attack.

The Stroke Association said it feared that thousands of people could be at risk of severe disability, or even stroke related death, if they didn't act on symptoms.

The warning came as Public Health England released its emergency department syndromic surveillance system (EDSSS) weekly statistics, which show that in the week ending 29 March there were only 89584 attendances, down $25 \%$ in the week since the covid-19 restrictions. ${ }^{12}$ The figures do not count stroke specifically.

Latest figures from Public Health England showed that emergency department attendances dropped by $34.5 \%$ on the same week last year, while Public Health Scotland figures showed a $40.1 \%$ reduction for the same time period.

Although figures for emergency admissions aren't available yet, the Stroke Association expects similar declines. Juliet Bouverie, its chief executive, said, "The fear of contracting the virus or feeling like a burden on the NHS might be the main reasons putting people off seeking treatment.

"But I am reassured that the NHS is well equipped to treat both stroke and coronavirus." She said that anyone who thought that they or someone they were with was having a stroke should call 999 and "assume stroke until told otherwise."

She added, "Equally concerning is people who experience mini-stroke and then dismiss it as 'just a funny-turn.' A mini-stroke is a warning that a major stroke is on its way, so you shouldn't ignore the signs and you need to seek help." David Hargroves, national clinical lead for the Getting It Right First Time programme's stroke workstream and a consultant stroke physician at East Kent University Hospitals, said that stroke care would be delivered very differently in the coming months. He said, "This may include different environments patients are cared for in, virtual assessments, therapy advice, or interventions delivered by telephone or video link.

"Members of the public should be reassured that these changes will help reduce the transmission of the virus, whilst continuing to provide the care that will save lives and reduce disability. It is so vitally important that they continue to seek help when they first spot the symptoms or signs of a stroke."

Public Health England. Emergency department syndromic surveillance system: England. 1 Apr 2020. https://assets.publishing.service.gov.uk/government/uploads/system/uploads/ attachment_data/file/877600/EDSSSBulletin2020wk13.pdf.pdf.

2 Thornton J. Covid-19: A\&E visits in England fall by 25\% in week after lockdown. BMJ 2020;369:m1401.

Published by the BMJ Publishing Group Limited. For permission to use (where not already granted under a licence) please go to http://group.bmj.com/group/rights-licensing/ permissions 